\title{
Providing calves different feed source early in life would not affect feed sorting and rumen fermentation for a long term
}

Jianxin Xiao (D 1016249009@qq.com )

China Agricultural University https://orcid.org/0000-0002-3074-5973

Muhammad Zahoor Khan

China Agricultural University

Gibson Maswayi Alugongo

China Agricultural University

Wei Wang

China Agricultural University

Yajing Wang

China Agricultural University

\section{Zhijun Cao}

China Agricultural University

Shengli Li

China Agricultural University

\section{Research}

Keywords: calf, concentrate, hay, feed sorting, rumen fermentation

Posted Date: May 11th, 2020

DOl: https://doi.org/10.21203/rs.3.rs-19008/v2

License: (9) This work is licensed under a Creative Commons Attribution 4.0 International License.

Read Full License 
The authors have withdrawn this preprint from Research Square 